\title{
WBT Content for Geography and Geology using VRML
}

Goro Akagi, Koichi Anada, Youzou Miyadera, Miyuki Shimizu, Kensei Tsuchida, Takeo Yaku, Maya Yasui

Nihon University, Waseda University Senior High School, Tokyo Gkugei University,

Nihon University, Toyo University, Nihon University, Nihon University

Abstract: In this paper we report on WBT content for geography and geology using VRML. We also propose an idea of WBT content for local area study that has not yet been implemented and discuss its effect from the viewpoint of knowledge management.

Keywords: e-Learning, WBT, geography, geology, VRML.

\section{INTRODUCTION}

From the National Curriculum Standards for lower secondary schools (http://www.mext.go.jp/b menu/shuppan/sonota/990301/03122602.htm), an important purpose of geographical education is to train students to discover characteristics of their local areas by relating spatial data to the environment of the area and the activities of people living there. To achieve this purpose, it is quite important to give experiences of finding out scenes of areas to learners by using maps and statistical data, so atlases and statistical sourcebooks are often used as teaching aids in geographical education at junior high schools.

We assert that 3D Computer Graphics (3DCG) can be applied to geographical education, because 3DCG can provide a more intuitive understanding of maps than paper-based educational material, and they improve learners' motivation to study geography and geology. From such a point of view, we experimentally developed Web Based Training (WBT) content using 3DCGs for geography and geology.

In this paper, we give an overview of our WBT content and report high school teachers' evaluation of it. Our WBT content includes 3D landform maps written in Virtual Reality Modelling Language (VRML) to explain the 
characteristics of landforms and topics in geography and geology. Here, a 3D landform map means a 3DCG of a landform.

In the next section, a preliminary a discussion of 3D landform map is provided. In Section 3, we give an overview of the experimental WBT content we made, and in Section 4, we propose an idea of WBT content for local area study that has not yet been implemented and discuss the effect of the content from the viewpoint of knowledge management. Section 5 is devoted to a brief evaluation of our WBT content. In the final section, we discuss conclusions and further research.

\section{PRELIMINARY: 3D LANDFORM MAP}

The experimental WBT content that we made up includes 3D landform maps, which are 3DCGs of landform maps. These maps are written in VRML and were generated from numerical altitude data with different mesh sizes (i.e., $50 \mathrm{~m}, 250 \mathrm{~m}$, and $1 \mathrm{~km}$ ) published by the Geographical Survey Institute (http://www.gsi.go.jp/ENGLISH/index.html). We employed several programs that automatically produce VRML files of 3D landform maps from numerical altitude data, and were developed by ourselves (see Anada, Kobayashi, Tsuchida, Miyadera, Motohashi and Yaku 2004).

Learners can browse 3D landform maps by using common Web browsers (e.g., Internet Explorer, Netscape and Firefox) with VRML plug-ins (e.g. Cortona (http://www.parallelgraphics.com/products/cortona/)) interactively changing viewpoints in $3 \mathrm{D}$ landform maps by moving a mouse (or a pointer device).

\section{WBT CONTENT}

In this section, we give an overview of the experimental WBT content we made. Our WBT content consists of the following: "Indexed glossary of geography and geology", "3D Inou-zu" (Inou-zu is the old Japanese map drawn by Tadataka Inou in the early $19^{\text {th }}$ century) and "History and 3D landform map". The number of files used for each kind of content is shown in Table 1.

\subsection{Features of the WBT Content}

The most important features of WBT content are the following: each item is written in HTML or Javascript, VRML, or JPEG, so it can be exhibited on the Web and browsed by using normal Web browsers (see Fig. 1); learners can interactively move 3D objects and viewpoints in 3D landform maps, so they can view one object from various points of view; each item is completely independent, so learners can freely choose among courses. We 
provided the last feature, because atlases and statistical sourcebooks are used in a similar way in junior high school geography classes.

Table 1. The number of files in each content (2005.10.31)

\begin{tabular}{|l|l|l|l|}
\hline & HTML file & VRML file & Other image file \\
\hline Indexed glossary & 192 & 122 & 25 \\
\hline 3D Inou-zu & 24 & 39 & 26 \\
\hline History and 3D landform map & 8 & 40 & 3 \\
\hline Frame and others & 28 & 0 & 24 \\
\hline Total & 252 & 201 & 78 \\
\hline
\end{tabular}

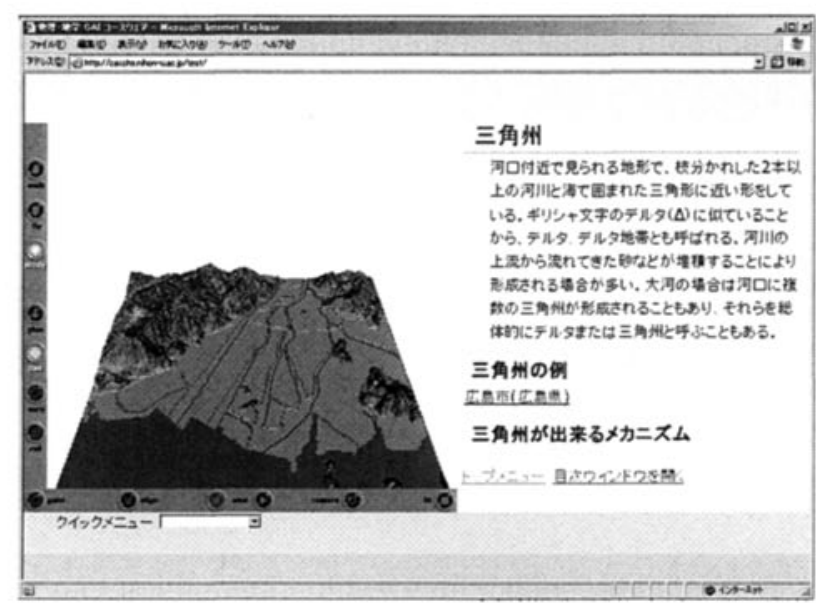

Figure 1. Screen shot of Internet Explorer displaying the WBT content (indexed glossary of geography)
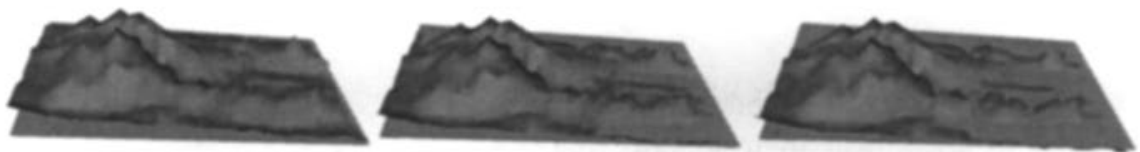

Figure 2. 3DCG explaining the mechanism of creating a ria coast. Learners can move the plane of the sea level by using a mouse.

The educational materials we made are regarded as WBT content because of the first feature. Furthermore, we also provided the second and third to achieve the purpose of geography education described in Section 1.

\subsection{Indexed Glossary of Geography and Geology}

Our indexed glossary of geography and geology included 81 words as of October 31, 2005. Each page includes one word and an explanation of it. We also made 3DCGs to help learners understand the explanations and attach them to the page. For example, a ria coast is a deeply embayed coast formed by a partial submergence of a landmass. To explain this, we made a simple 3D landform map of mountains and valleys with the plane of the sea level, 
and learners can interactively observe how the coast changes by moving the plane of the sea level (see Fig. 2).

\subsection{D Inou-Zu}

We produced a 3D landform map and mounted textures of the Inou-zu, which is an old Japanese map drawn by Tadataka Inou in the early $19^{\text {th }}$ century (Edo period), on it. This content helps learners to relate geography to history

\subsection{History and 3D Landform Map}

On Aug., 7, 1945, the old Japanese navy arsenals located in Toyokawa were bombed by the United States, and many Japanese were died there. We re-created the arsenals by using VRML. This content is not yet completed, and we plan to add information, e.g., the usage of each building, to a 3D landform map of Toyokawa. Learners will be able to experience the past.

\section{CONTENT FOR LOCAL AREA STUDY}

In this section, we give an idea of content for local area study, which has not yet been implemented. Moreover, we also mention the effects of the content from the viewpoint of knowledge management.

\subsection{Idea of Content}

Area studies are important in education for elementary school students in Japan. Students plan research and go out to areas near their schools, e.g., shopping arcade, farm, to collect information from people working there and view the information from various angles. A deeper understanding of their local areas results from such research experiences.To aid area studies, we propose 3D content, e.g., 3D virtual shopping arcades, 3D virtual high-rise buildings, and 3D virtual forests, that work as the interface of a 3D database. More precisely, learners can store information on their areas in the 3DCGs. We give a couple of example of such content in the following.

The usage of high-rise buildings: The usage of each floor in a high-rise building is correlated with the height of the floor, i.e., lower floors are used for shopping malls, banks, and so on, while, upper floors are used for offices and hotels, and the top floor is for restaurants and observatories. Learners find out about such correlation by arranging information on the usages of $3 \mathrm{D}$ virtual high-rise buildings.

Distribution of creatures in forests: Learners can find out the how creatures, i.e., plants, insects, and animals, are distributed in neighbouring forests by observing in forest areas and arranging data in a $3 \mathrm{D}$ virtual forest. 
The content from learners can be shared over the Internet, so learners can understand the differences and similarities among areas (see Fig. 3).

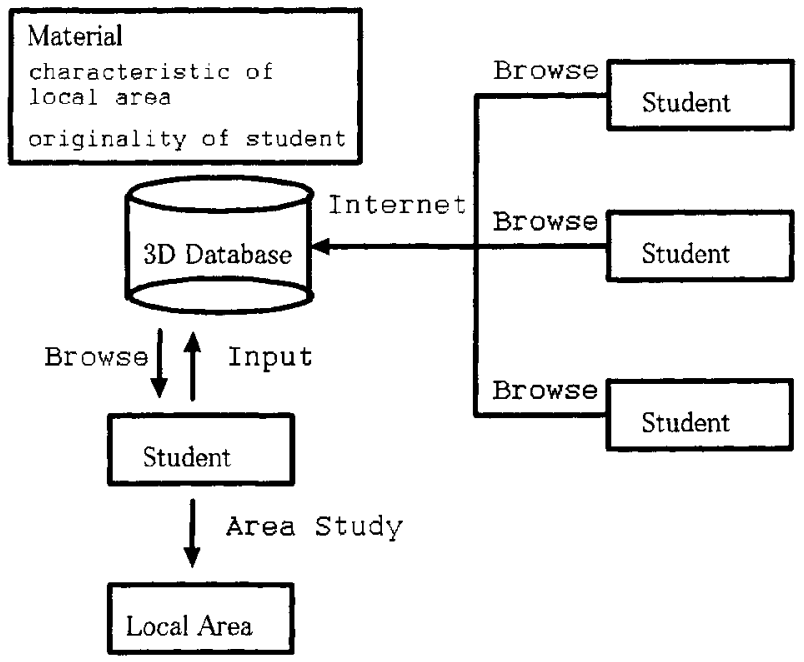

Figure $33 D$ database and applications to area study

\subsection{Effect of Content from the Viewpoint of KM}

Knowledge Management (KM for short) has recently become important in education. According to Ogushi (2003), the previous educational method in Japan makes much of the stages of Combination and the Internalization, but not of Socialization and the Externalization of Nonaka's SECI model (Ogushi 2003); however, the stages of Socialization and Externalization play an important role in $\mathrm{KM}$ for educational innovations. We propose an application of our content described above to help local area studies at these two stages. In our content above, students have occasion to extract and show the characteristics of local areas, and such activities bring the Socialization of tacit knowledge and the Externalization of such tacit knowledge to become explicit. Furthermore, students can combine the explicit knowledge by comparing their works each other, and deepen understanding of the characteristics of local areas. This implies the Internalization of explicit knowledge. Therefore, the content for local area study provides cycles that appeared in the SECI model.

\section{EVALUATION}

We asked a couple of teachers at Waseda University Senior High School to evaluate our WBT content. Some of their comments are as follows:

a) Usually, pictures of landforms are used in geography class. 3D landform maps provide views from more sides and provide more intuitive understanding of topographies to students than pictures can. 
b) 3D landform maps could also be applicable to studies on the urbanization of rural areas.

c) The WBT content could be useful for self-study by students.

d) The measurement on a 3D landform map could enrich the WBT content, and metro areas and underground shopping arcades are also good materials for this WBT content.

\section{CONCLUSIONS AND FUTURE RESEARCH}

Our WBT content is just a glimpse into the great potential of multimedia content as an educational tool. In particular, a 3D landform map written in VRML has the significant features: convenience of viewing, operation and creation, and rich interaction for learners. The method used here can be applied to WBT content for various subjects.

We now plan to develop content of geography and geology based on the results of the high school teachers' evaluation. Moreover, we will also attempt to integrate our Web content with a Geographical Information System (GIS). This will enable us to provide more effective WBT content by using statistical data from GIS. Furthermore, we will develop more interactive methods for WBT.

\section{ACKNOWLEDGEMENTS}

The authors thank Mr. Jun Kobayashi, Mr. Taisuke Suzuki, Mr. Shingo Hinata and Mr. Hideki Wada at Nihon University and Ms. Kaori Suzuki and Mr. Yuichi Yamada at Toyo University for their fruitful discussions and assistance. The authors also express sincere gratitude to the teachers of Waseda University Senior High School, in particular, Mr. Toru Matsuzawa and Mr. Mamoru Takezawa, for their kind cooperation of evaluation of our WBT content

\section{REFERENCES}

Anada, K., Kobayashi, J., Tsuchida, K., Miyadera, Y., Motohashi, T. and Yaku, T. (2004). A 3-D display system and its data structure for geology education, Proceedings of the $29^{\text {th }}$ Annual Conference of Japanese Society for Information and Systems in Education, 117118.

Nonaka, I. and Takeuchi, H. (1991). The Knowledge Creating Company: How Japanese Create The Dynamics of Innovation, NY: Oxford University Press.

Ogushi, M. (2003). Knowledge management for education, Proceedings of the $38^{\text {th }}$ Annual Conference of Japan Educational Administration Society. 